\title{
Claroscuros de un estadunidense en México: el caso de Paul Hudson (1896-1921)
}

\section{Ups and Downs of an American in Mexico: The Case of Paul Hudson (1896-1921)}

\author{
Iñigo Fernández Fernández \\ (D) 0000-0003-2654-8018 \\ Universidad Panamericana \\ Campus Ciudad de México, México \\ infernan@up.edu.mx
}

Resumen: El presente trabajo se centra en Paul Hudson, figura destacada de la colonia estadunidense en el México porfirista que ha sido escasamente estudiada en nuestro país. A través del análisis de testimonios hemerográficos de la época, nos proponemos demostrar que Hudson logró consolidar una imagen de prohombre en el país gracias a los servicios que prestó al régimen de Porfirio Díaz por medio del periódico The Mexican Herald, a su participación en negocios organizados por los capitales mexicanos y estadunidenses y a su colaboración en proyectos filantrópicos. De igual manera, explicaremos que su lealtad al régimen porfirista, el rechazo a la revolución mexicana y el apoyo a la invasión estadunidense al país marcaron su declive como figura pública y su posterior salida del país.

Palabras clave: Paul Hudson; Mexican Herald; porfiriato; economía; filantropía.

Abstract: This article focuses on Paul Hudson, a key figure in the North American colony in Porfirian Mexico that has barely been studied in our country. Through the analysis of hemerographic testimonies of the time, we attempt to show that Hudson managed to consolidate an image of an upstanding citizen in the country as a result of the services he rendered to Por- 
firio Díaz's regime through the newspaper The Mexican Herald, his participation in businesses organized by Mexican and North American capitals and his collaboration in philanthropic projects. We will also explain that his loyalty to the Porfirian regime, rejection of the Mexican Revolution and support for the US invasion of the country led to his decline as a public figure and his subsequent departure from the country.

Key words: Paul Hudson; Mexican Herald; porfiriato; economy; philanthropy.

\section{INTRODUCCIÓN}

finales de octubre de 1896 arribó a la ciudad de México un joven pe-
riodista procedente de Topeka, Kansas. Su nombre era Paul Hudson Smith y el motivo de su viaje era hacerse cargo de la gerencia de The Mexican Herald, periódico escrito en inglés que se estaba perfilando como el preferido de la comunidad estadunidense (Schell, 2001) y en uno de las más leídos por los mexicanos que sostenían vínculos con ella.

La llegada de Hudson al país se dio en un tiempo de cambios acelerados y trascendentes para la prensa en México. Meses atrás, el periodista Rafael Reyes Spíndola había iniciado la publicación de El Imparcial, el primer diario industrial y moderno en México cuya existencia marcó, además, el fin de El Siglo XIX y de El Monitor Republicano, representantes por excelencia de una prensa política decimonónica que ya había visto pasar sus mejores tiempos.

A partir de entonces, los lectores mexicanos se fueron acostumbrando a un modelo de periodismo importado de Estados Unidos en el que las noticias tenían una mayor relevancia que las editoriales, donde las historias de interés humano empezaron a ocupar más espacios y en el que la apariencia física revistió gran importancia al convertirse en uno de sus mayores atractivos (González Navarro, 1990; Lepidus, 1928; Pérez-Rayón, 2001). Tal como lo veremos más adelante, los cambios generados por este nuevo periodismo, aunados a las ayudas gubernamentales, coadyuvaron a la proliferación de publicaciones periódicas a lo largo y ancho del país.

De igual forma, esta fue una época en la que proliferó la prensa en lengua extranjera. Si bien la publicación de este tipo de periódicos no era un

\section{()(1) $(3$}


fenómeno nuevo, ${ }^{1}$ sí lo era, en cambio, el hecho de que estas se consideraran, y el Herald no fue la excepción, como los portavoces a la par que testigos de las distintas comunidades extranjeras asentadas en el país y cuyo número de miembros crecía al mismo ritmo con el que lo hacían los lazos comerciales entre México y las naciones industrializadas.

El joven Hudson se había formado como periodista en Estados Unidos a inicios de los años noventa del siglo xix, en una época en la que, según Douglas (1999), los periódicos estadunidenses en las grandes urbes:

se estaban convirtiendo rápidamente en grandes negocios [...]. La nación se fue alejando de las viejas formas agrarias hacia las nuevas y a menudo desconcertantes valores de una sociedad urbana. Fue una época de triunfo de los negocios, del capitalismo rampante, una época de grandes corporaciones [...] de los trusts, de la banca de inversión, de los magnates ladrones y de los millonarios que brincaron de la pobreza a la riqueza (p. 81).

Del mismo modo como el periodismo iba estrechando sus vínculos, entrelazándose, con los grandes intereses económicos, que hacían las veces de su motor, tampoco era de extrañar que quienes se dedicaran al periodismo hicieran lo propio. Pese a que los procesos mencionados apenas iniciaban en México a finales del siglo XIX, ya estaban dadas las condiciones para que esta relación pudiera darse.

Al menos Hudson así lo entendió, pues con el paso de los años se fue involucrando en negocios organizados con capitales mexicanos y estadunidenses a la par que aumentó su presencia en eventos sociales y filantrópicos de relevancia -donde el aspecto económico no era necesariamente dominante, pero también se hallaba presente-. Poco a poco estas actividades lo fueron posicionando como un personaje prominente al interior de la comunidad estadunidense y en el seno de la elite económica, política y social mexicana de finales del siglo xix e inicios del xx. Precisamente esta cercanía con el régimen porfirista fue uno de los factores que marcó el declive de su periódico con el estallido de la revolución y uno de varios argumentos utilizados por los detractores de Hudson para tildarlo de traidor a México.

${ }^{1}$ Como The American Eagle, The American Star, The North American, Le Trait d'Union, L'Ere Nouvelle y L'Estafette, sólo por mencionar algunos ejemplos.

\section{()(1) $(9$}


La estancia de Hudson en México, sin embargo, presenta una contradicción. Como veremos en las siguientes páginas, nos hallamos ante una figura importante en el país pero que, al mismo tiempo, ha sido poco trabajada por los historiadores como consecuencia, tal vez, de la falta de fuentes. ${ }^{2}$ Algunos textos, como A community of modern nations: The Mexican Herald at the height of the porfiriato 1895-1910, de Joshua Salyers (2011), y "The Mexican Herald: Outpost of empire, 1895-1915”, escrito por Jerry Knudson (2001), centran más su interés en el periódico que en Hudson; en tanto que William Schell (2001), en su libro Integral Outsiders. The american colony in México City, 1876-1911, dedica unas pocas páginas y párrafos sueltos para referirse a él.

Es precisamente en el marco de esta laguna que nos planteamos las siguientes preguntas: ¿qué recursos utilizó Hudson para construir su imagen de "prohombre" en México entre 1896 y 1910? Y, a manera de contraste, ¿qué factores fueron los que propiciaron su caída a partir de 1911?

Consideramos que un recurso que nos permitirá dar las primeras respuestas a estas interrogantes es el estudio de fuentes hemerográficas de la época. Así, nos dimos a la tarea de revisar los siguientes acervos digitalizados: Arizona Digital Newspaper Program, California Digital Newspaper Collection, Colorado Historic Newspapers Collection, Google News, Hemeroteca Nacional Digital de México, Newspapers.com, NYS Historic Newspapers Project, Portal to Texas History, y State Historical Society of Missouri Digital Collection.

Para los efectos del presente texto, iniciaremos con una pequeña biografía de Paul Hudson, continuaremos con un estudio sobre su estancia en México entre 1896 y 1910 y, por último, analizaremos el periodo 1911-1921, que representa su momento de declive.

2 Suponemos que la desaparición del archivo personal de Hudson -si es que alguna vez hubo tal-y de los registros del periódico podrían explicar, al menos en origen, esta situación.

\section{()(1) $(3$}




\section{ALGUNAS CONSIDERACIONES SOBRE LA VIDA DE PAUL HUDSON Y ESTADOS UNIDOS DE FINALES DEL SIGLO XIX E INICIOS DEL XX.}

Paul Hudson Smith nació en Rosedale, Kansas, en mayo de $1870^{3}$ y pasó gran parte de su infancia y su juventud en la ciudad de Topeka, Kansas. Sus padres fueron Mary Worrall Smith (1840-1930) y Joseph Kennedy Hudson (18401907), ambos originarios de Ohio y partidarios del abolicionismo. La pareja contrajo nupcias en $1863^{4}$ y tuvo cuatro hijos: ${ }^{5}$ Mary Esther (1865-1948), Ada B. (1866-1868), Paul (1870-1932) y Anna Josephine (1873-1943).

Sobre la madre de Hudson, Connelley (1918) señala que no era persona ordinaria; por el contrario, solía redactar artículos para revistas y otras publicaciones periódicas e incluso llegó a escribir tres libros: From a station on the underground railroad, The story of an american family, $y$ Two little maids and their friends (Camp, 2014). Su padre fue una figura importante en Kansas, y en especial en la vida de la ciudad de Topeka. En la guerra de Secesión se sumó a la causa abolicionista bajo las órdenes de los generales Davis, Lane y Schofield y alcanzó el grado de general. Con la llegada de la paz, se dedicó a la agricultura, la política y el periodismo. Sobre este último aspecto, en 1873 compró la publicación quincenal Kansas Farmer al Departamento de Agricultura de Kansas y la transformó en un semanario. No conforme con ello, el 21 de abril de 1879 "fundó el diario Topeka Daily Capital, del que fue su editor en jefe durante casi 20 años"; ${ }^{6}$ labor que combinó con la militancia en el Partido Republicano y con el ejercicio de cargos públicos -como los de impresor del estado de Arkansas, secretario de la Junta de Agricultura en Kansas y representante en la legislatura estatal. ${ }^{7}$

En virtud de lo anterior, no debe extrañarnos que, en 1891, y tras finalizar sus estudios en la Universidad de Kansas, Paul Hudson se integrara al equipo de trabajo del Topeka Daily Capital donde inició su vida periodística

${ }^{3}$ Véase https://www.familytreenow.com/

${ }^{4}$ Joseph Kennedy Hudson papers. State Archives. Kansas Historical Society. Recuperado de http://www.kshs.org/archives/40395

${ }^{5}$ Véase https://www.familytreenow.com/

${ }^{6}$ Joseph Kennedy Hudson papers. State Archives. Kansas Historical Society. Recuperado de http://www.kshs.org/archives/40395

${ }^{7}$ Joseph Kennedy Hudson papers. State Archives. Kansas Historical Society. Recuperado de http://www.kshs.org/archives/40395 
como reportero de siniestros. ${ }^{8}$ Un año más tarde contrajo nupcias con Augusta Price con quien procreó tres hijos, a saber: Pauline (Topeka, Kansas, 1894-?), Donald (Topeka, Kansas, 1895-1967) y Helen Marie (ciudad de México, 1901-1944). ${ }^{9}$

En 1895, Hudson decidió seguir el ejemplo paterno. Fundó y dirigió Modern Mexico, una revista ilustrada de carácter mensual cuyos contenidos estaban pensados para el mercado de Estados Unidos y comprendían temas económicos, políticos y literarios vinculados con el vecino del sur (Schell, 2001). ¿Qué llevó a un joven originario de Kansas a interesarse por México?, y ¿cuándo nació este interés?, son preguntas a las que no podemos responder por el momento.

No fue sino hasta finales de octubre de 1896 cuando viajó a México. Los periódicos The Mexican Herald, El Mundo y Two Republics notificaron de manera escueta su arribo. El primero publicó una nota en la que apuntaba que "Paul Hudson, editor de Modern Mexico, de Topeka, Kansas, llegó a esta ciudad en un viaje de negocios y placer. Espera quedarse en la república unas tres semanas"; ${ }^{10}$ en cambio, el segundo ${ }^{11}$ destacó el carácter exclusivamente comercial de su viaje, y con ello se aproximó más a la verdadera naturaleza de su misión, pues Hudson venía para ser nombrado administrador de The Mexican Herald, puesto que dejaría en 1908 para convertirse en el presidente de la publicación.

Sus actividades en la ciudad de México aumentaron con relativa rapidez, de ahí que debiese combinar los menesteres propios de la tinta y el papel con otros vinculados con la economía, el altruismo y las actividades sociales. Se desempeñó como "presidente de la Publicity and Publishing Company of Mexico, fundador y presidente de la American School, director de la Mexican Society of New York, presidente [y también vicepresidente] del Mexico City University Club, miembro fundador del Mexico City Country Club, director de la Mexico City Banking Company, y la fuerza impulsora detrás de la Tropical Plantation Association of Mexico" (Schell, 2001, p. 14). Estos

8 “Es eficaz para México su cuerpo de bomberos?”, El Diario, 17 de febrero de 1910, pp. 1 y 4 .

9 Paul Hudson. Recuperado de https://www.ancestry.co.uk/genealogy/records/paulhudson_98846716; “Falleció la hija del periodista Paul Hudson”, El Porvenir, 23 de marzo de 1944 , p. 5.

10 "Personal", The Mexican Herald, 24 de octubre de 1896, p. 8.

11 “Notas”, El Mundo, 24 de octubre de 1896, p. 3. 
cargos, al igual que la variedad de intereses que se encontraban detrás de ellos, son un fiel reflejo de los tiempos que se estaban viviendo tanto en Estados Unidos como en México, pues del mismo modo que las fronteras entre la economía, la política y la sociedad se iban desdibujando en las páginas de los grandes diarios de ambas naciones, también cabía esperar lo mismo entre quienes estaban a cargo de dirigir los destinos de estas publicaciones.

Hudson siempre se mostró leal al gobierno de Porfirio Díaz de distintas maneras. Por un lado, puso al Herald a su servicio y lo alineó a sus intereses y, por el otro, no dudó en publicar en él entrevistas en las que hablaba favorablemente de la estabilidad del gobierno mexicano y de los beneficios que este había generado a México. Su adhesión al régimen fue tal que Mayagoitia (2005) afirma que llegó a participar en una manifestación organizada por la colonia estadunidense a favor de la reelección de Díaz para el periodo 1900-1904.

El apoyo mostrado a la administración porfirista, así como la negativa a otorgárselo al gobierno de Francisco I. Madero, fueron factores que favorecieron que Hudson cayera en desgracia durante la revolución. Tras la clausura definitiva del Mexican Herald, en agosto de 1915, viajó a Estados Unidos, donde formó parte de la Asociación para la Protección de los Derechos de los Estadunidenses en México y, según lo refiere Schell (2001), se integró como editor al Washington Post hasta su muerte, ocurrida en 1950.

Hudson nació cinco años después del fin de la guerra de Secesión, en la "era de la reconstrucción" de Estados Unidos, creció e inició sus actividades profesionales en México durante la "época dorada", las consolidó y concluyó en la "época progresista". Estos tres momentos, que abarcan de 1865 a 1918, marcaron el camino para que Estados Unidos lograra consolidarse como potencia mundial en el siglo xx.

Este fue el tiempo en que la nación creció territorialmente, no sólo a través de la ocupación paulatina, pero constante, del oeste, también gracias a una política expansionista que le llevó a controlar Filipinas, Guam, Hawái y otras islas del Pacífico; a independizar Cuba, Puerto Rico y Panamá, al tiempo que invadir temporalmente a otras naciones del contienente americano (México, República Dominicana...) y mantener una política de puerta abierta con China.

Este crecimiento se vio favorecido por el empuje de una economía que se encontraba en pleno proceso de crecimiento industrial. La constitución del ferrocarril en una red nacional, el uso de la energía eléctrica y de la maquinaria de combustión interna, el surgimiento de los trusts no sólo hicieron

\section{()(1) $(9$}


que Estados Unidos fuera la primera potencia industrial del mundo en 1910 (Walton y Rockoff, 2014, p. 301), también ayudó a incrementar la riqueza nacional y el consumo interno, consolidar la publicidad en la prensa, a acelerar el proceso de crecimiento de las ciudades, favorecer la llegada de más migrantes, aumentar los índices educativos, y transformar el país en una nación acreedora (lo que, a su vez, transformó el equilibrio en la balanza de pagos mundial) que mantenía una postura activa en el concierto de las naciones.

Este proceso acelerado de industrialización generó variaciones en la esfera de lo social. Los campesinos tuvieron que recurrir al financiamiento para sembrar y al ferrocarril para comerciar su cosecha, situación que los obligó a soportar, primero, y combatir, después, la usura por parte de los bancos y de los prestamistas y los abusos de las compañías ferrocarrileras. En las ciudades, los artesanos se convirtieron en obreros y los antiguos patrones devinieron en directores cuyo interés radicaba en la generación de mayores dividendos para sus empresas - muchas de ellas integradas ya en trusts-. Lo anterior fue un campo de cultivo para la formación de sindicatos, como la Noble Orden de los Caballeros del Trabajo (Walton y Rockoff, 2014); la organización de huelgas, que muchas veces tomaban tintes violentos; la postulación de leyes progresistas por parte de los gobiernos locales que, generalmente, eran detenidas por la Suprema Corte de Justicia, y la migración de millones de personas procedentes de Alemania, Canadá, Europa central, Irlanda, la península escandinava, Rusia..., que viajaban a "la nueva tierra prometida" en aras de alcanzar mejores condiciones de vida, pero que no siempre eran bien recibidos.

El Estados Unidos de Hudson era una nación que transitaba de la reconstrucción a la prosperidad, del campo a la ciudad y de lo regional a lo mundial; era un país con una economía en la que el campo y la industria se habían integrado, en la que los trusts se abrían paso a gran velocidad, y en la que el control sobre otras naciones se llevaba a cabo lo mismo a través del uso de las armas que por medio del capital y el comercio.

\section{LOS TIEMPOS LUMINOSOS DE PAUL HUDSON (1896-1910)}

Hudson empezó a ser conocido en México por sus labores como gerente del Mexican Herald. El diario había sido fundado en 1895 por Frederic R. Guer-

\section{()(1) $(9$}


nsey, un antiguo miembro del Boston Herald quien llegó a México como parte de la oleada de capitalistas bostonianos que había financiado al Mexican Central Railway. Poco después del arribo de Hudson (Schell, 2001), el Herald se hizo acreedor a un subsidio gubernamental de 12000 dólares anuales, con lo que se convirtió en una publicación de carácter oficialista que daba voz lo mismo a la colonia estadunidense que a la administración de Díaz.

Desde el primer momento no dudó en poner su impronta en el periódico, particularmente en el desarrollo de los programas de publicidad para sus colegas extranjeros. Según Schell (2001), Hudson "convirtió en un arte el cuidado y la atención de los periodistas al proveerlos con guías sobre todos los temas de interés y suministrándoles boletines de prensa y materiales de investigación y de referencia" (p. 15), y, con ello, consiguió tener un gran control sobre el producto final al tiempo que interconectó los intereses de los empresarios estadunidenses, la embajada de Estados Unidos y el gobierno mexicano.

Esta situación lo obligaba a ser cuidadoso en los contenidos del Herald. Recibía un jugoso apoyo económico del gobierno mexicano al tiempo que sabía que la información que publicaba era enviada por el embajador de Estados Unidos al Departamento de Estado. Entendió pronto que una de las finalidades del periódico era la de ser un medio informal de comunicación entre los gobiernos al norte y al sur del río Bravo, por lo que en ocasiones el diario se mostraba en desacuerdo con algunas acciones tomadas en Washington mientras que en otras las defendía. Lo anterior nos permite comprender los motivos que tuvo Hudson para que el diario no promoviera el imperialismo estadunidense $y$, en su lugar, difundiera una idea de panamericanismo basada en la exaltación de los beneficios que generaría la cooperación económica entre México y Estados Unidos (Salyers, 2011).

Salyers también destaca el interés que tuvo Hudson para que el Herald promoviera la modernidad en México. Lejos de fomentar la adopción de los patrones culturales de Estados Unidos, durante dos décadas aspiró a que los nacionales se acercaran más a su cultura pues aseguraba que "los principios de la modernidad existían al margen de los contextos regional e, incluso, nacional" (Salyers, 2011, p. 47). Nos hallamos ante una situación un tanto contradictoria pues mientras que la elite porfirista aspiraba al triunfo de los valores modernos a través de la erradicación de las costumbres y prácticas tradicionales mexicanas, el estadunidense defendía la idea de que el pasado prehispánico daba al país una legitimación histórica que marcaba el papel preeminente que México debía ejercer en Latinoamérica, gracias al uso de

\section{()(1) $(9$}


frases como "La civilización maya [es] considerada como la más avanzada que la de las regiones adyacentes"12 o "En las civilizaciones sometidas por las tribus aztecas, el arte es de un orden superior". ${ }^{13}$

A reserva de lo anterior, también procuró que el Herald fuera un referente del periodismo nacional por su carácter vanguardista. Así, no sólo consiguió que el suyo fuera el primer periódico en el país que dispusiera de los servicios de la Associated Press (AP), también fundó en 1906, y en compañía de El Diario y El Imparcial, la sucursal de esta en la capital del país. ${ }^{14}$

El afán constante por innovar lo llevó a considerar la posibilidad de hacer una versión en castellano de su diario, al que muchos consideraban como una de las mejores publicaciones periódicas de la ciudad de México a inicios del siglo xx. Aspiraba a aumentar el número de lectores y promover su visión de México como país, muy similar a la que tenían la comunidad estadunidense y el gobierno nacional. Sabemos que en 1906 hizo un intento para concretar esta idea cuando le propuso al gerente de El Diario, que recién se acababa de trasladar de la frontera a la ciudad de México, la compra de 51\% de las acciones del periódico y el cambio de nombre a El Heraldo Mexicano. ${ }^{15}$

Aunque la transacción jamás llegó a concretarse, ello no fue un impedimento para que Hudson continuara con su proyecto. Finalmente, el 8 de noviembre de 1910 el Diario Oficial publicó una carta que Hudson dirigía al secretario de Instrucción Pública y Bellas Artes en la que le notificaba: "que mi representada [The Publishing Company of Mexico] ha resuelto publicar un diario de la tarde, que será edición vespertina del mencionado The Mexican Herald, el que se redactará en castellano y se denominará El Heraldo Mexicano". ${ }^{16}$ Tenía un costo de dos centavos y empezó a circular en las calles de la capital el mismo mes de noviembre, sin embargo, su existencia fue efímera como consecuencia del estallido de la revolución mexicana.

La labor periodística de Hudson tuvo otra faceta que, si bien estaba lejos de los despachos, no por ello nos resulta menos interesante: la promoción de México entre los periodistas estadunidenses. Recién asentado en el país,

12 "Mayan civilization", The Mexican Herald, 18 de noviembre de 1906, p. 20.

13 "Aztec pottery at Columbia", The Mexican Herald, 19 de noviembre de 1912, p. 6.

14 "Cómo fue fundada en México la sucursal de la Prensa Asociada", El Diario, 11 de octubre de 1906, p. 1.

15 "Cómo fue fundada en México la sucursal de la Prensa Asociada", El Diario, 11 de octubre de 1906, p. 1.

${ }^{16}$ Diario Oficial. Estados Unidos de México, 8 de noviembre de 1910, p. 68.

\section{(1) (1)}


se integró a las comisiones que daban la bienvenida a aquellos colegas estadunidenses que eran invitados por Díaz para que visitaran México. Con el paso de los años, su posición mejoró hasta que, en julio de 1910, recibió del propio Díaz la instrucción de invitar "a los periodistas de aquella república [Estados Unidos] para que nos visiten durante las fiestas del centenario", encomienda que aceptó "y en cumplimiento de la comisión que se le confiere, ha hecho las invitaciones, que en su mayoría han sido acogidas con agrado". ${ }^{17}$

Las gestiones de Hudson dieron fruto pues cinco periodistas de $\mathrm{Ca}-$ nadá y 37 de Estados Unidos llegaron a la capital y fueron agasajados por sus autoridades políticas y por miembros de la prensa mexicana. ${ }^{18}$ El Tiempo publicó una lista que consigna los nombres de algunos de los periodistas y de los periódicos que respondieron a este llamado, y que a continuación presentamos: ${ }^{19}$

1. Albert Hale, representante del Boletín de la Oficina de las Repúblicas Americanas, de Washington.

2. Albert Shaw, representante de la Review of Reviews, de Nueva York.

3. Arthur W. Page, representante del World's Work, de Nueva York.

4. C. A. C. Jannings, representante del Toronto Mail and Empire.

5. C. S. Gleed, copropietario del Kansas City Journal.

6. C. T. Pearce, representante del Toronto News.

7. Chester T. Crowell, representante del San Antonio Express.

8. Clinton Collier, representante del Chicago Record.

9. E. A. Ditmar, representante del New York Times.

10. Edwin W. Beedle, representante del World Today.

11. Frank P. Lennan, propietario del Topeka State Journal, de Kansas.

12. George Buchanan Fife, representante del Harper's Weekly, de Nueva York.

13. Hamilton Holt, representante del Independient, de Nueva York.

14. Ira E. Bennet, representante del Washington Post.

15. J. A. Gauthier, representante de La Patrie, de Montreal.

16. J. A. McDonald, representante del Toronto Globe.

17. J. C. Edgerly, representante del Boston Journal.

18. J. P. Dwyer, representante del Philadelphia Record.

\footnotetext{
17 “Vendrán varios periodistas de los Estados Unidos”, El Tiempo, 26 de julio de 1910, p. 1.

18 "Los periodistas americanos", El Correo Español, 14 de septiembre de 1910, p. 2.

19 “Sección del centenario", El Tiempo, 10 de septiembre de 1910, p. 2.
} 
19. Lafayette Young, propietario del Des Moines Capital.

20. R. W. Vicent, representante del Wall Street News Bureau, de Nueva York.

21. Rafael O. Galván, representante de Las Novedades, de Nueva York.

22. Robert D. Heinl, representante del Leslie's Weekly, de Nueva York.

23. Robert E. Mac Alarney, representante del New York Evening Post.

24. Samuel Bowles, representante del Springfield Republican, de Massachusetts.

25. Scott Bone, editor del Washington Herald.

26. Smeaton White, representante del Montreal Gazette.

27. Thomas H. Blodgett, representante del Outing.

28. Tilden Adamson, representante del Brooklyn Eagle, de Nueva York.

29. Victor Murdock, editor del Eagle, de Wichita, Kansas.

30. Victor Rosewater, propietario del Omaha Bee.

31. Wallace Gilpatrick, representante del Outlook.

32. William E. Brigham, representante del Boston Transcript.

33. William G. Sterett, representante del Dallas News.

Sin importar los años que llevara avecindado en México, Hudson no había perdido contacto con el medio periodístico estadunidense. A las publicaciones de su natal Kansas, cuya inclusión es comprensible, se suman otras de renombre, como el New York Times y el Washington Post, lo que pone de manifiesto tanto la importancia que estos otorgaban a los festejos del centenario de la independencia de México como el poder de convocatoria que Hudson tenía en Estados Unidos. Sobre este punto, destaca el énfasis que puso al invitar a representantes de periódicos y revistas neoyorkinos, lo que no podemos tomar como una mera coincidencia en virtud de que en ese tiempo la ciudad de Nueva York se estaba consolidando como uno de los centros fabriles, mercantiles y de comunicaciones de mayor importancia en la esfera mundial.

La anterior no fue la única manera en la que mostró su lealtad hacia el gobierno mexicano. Nunca dejó pasar la oportunidad de promover al régimen de Díaz en las entrevistas que otorgaba a los medios impresos estadunidenses. Con la llegada del nuevo siglo y el evidente envejecimiento del general mexicano -nacido en 1830-, Hudson cambió las formas mas no el fondo de su postura. En enero de 1910, el Herald reprodujo íntegramente una entrevista que The Baltimore Sun realizó a su presidente dos meses atrás con motivo de su visita a Washington. Ante la pregunta de ¿qué pasará con Mé-

\section{()(1) $(9$}


xico después de Díaz?, Hudson reconoció que el general mexicano era viejo y cada vez le costaba más trabajo gobernar, pero, al mismo tiempo, se refirió al legado que este dejaba al país pues "después de Díaz tendremos el espíritu de Díaz, la política de Díaz. [El] México moderno no aceptará nada menos." ${ }^{20}$

Lo anterior trasciende el ámbito de lo anecdótico por una razón. Los hechos referidos manifiestan la importancia que tenía Hudson para el presidente mexicano. Es bien sabido que durante su mandato, Díaz aspiró a mostrar una buena imagen de México en el extranjero, de ahí que siempre tuviera mucho cuidado en elegir a personas capaces y que gozaran del prestigio necesario para cumplir de manera cabal esta misión. Este fue el caso, por ejemplo, del sacerdote, y fututo obispo, Eulogio Gillow, a quien en 1884 nombró jefe de la delegación mexicana en la Exposición Mundial de Nueva Orleans y que, a la postre, fungió como una de las piezas clave en la conciliación entre el Estado y la Iglesia en el porfiriato.

Si Díaz escogió a Hudson como uno de sus interlocutores con la prensa estadunidense, ello no sólo se debió a su origen, a los servicios que el periodista brindó a su régimen o a la importancia que su periódico tenía en la capital del país; también debió ponderar la posición de este al interior de la comunidad estadunidense en México, misma que le hizo formar parte de lo que Schell (2001) llama la "mafia tropical", ese "círculo de promotores y hombres de negocios que llegaron a dominar la colonia [estadunidense] después de 1900" (p. 17).

Y es que en el último cuarto del siglo xix, y a raíz de la consolidación del régimen porfirista y del crecimiento del ferrocarril en el país, el intercambio de productos entre México y Estados Unidos aumentó considerablemente y las inversiones estadunidenses llegaron a niveles similares que las europeas. Para 1911 los capitales estadunidenses en México alcanzaban los 1292 millones de pesos, lo que representaba 38\% del total (Riguzzi, 1992, p. 371).

Aunque Hudson no fue uno de los miembros más acaudalados de la comunidad estadounidense, mostró la habilidad necesaria para asociarse con otros -estadunidenses, europeos y mexicanos-en negocios que poseyeron una gran rentabilidad o, bien, para convertirse en representante de instituciones estadunidenses destacadas que poseían intereses comerciales en

20 "Goverment of Mexico is firm as Rock of Gibraltar", The Mexican Herald, 12 de enero de 1910, p. 1.

\section{()(1) $(9$}


México. A continuación, haremos una breve revisión de los negocios en los que, según consignan las fuentes hemerográficas, Hudson participó.

En octubre de 1906 fundó la La Latino Americana, Mutualista, S.C. -hoy Latinoamericana Seguros, S. A.- en compañía de Óscar J. Braniff (su primer director), Guillermo de Landa y Escandón, Eduardo Liceaga, William Walter y James Harold Warner, entre otros tantos miembros más de la elite económica y política del país. Su creación correspondía a los tiempos de bonanza que vivía México y que le permitían "entrar francamente en el concierto de las naciones tranquilas y civilizadas", de ahí que la compañía aspirase a competir contra otras aseguradoras ofreciendo un extra que ninguna de ellas tenía: ser la única constituida en conformidad con las leyes nacionales. ${ }^{21}$

No sólo se trató de un ejercicio innovador que ofrecía seguros de vida, cuando aún eran poco conocidos, a las clases menos favorecidas (La Latinoamericana, 1996), también fue uno muy rentable pues el número de asegurados creció año tras año hasta que el capital social de la mutualista alcanzó, en 1910, los 500000 pesos, y se transformó en sociedad anónima (Collado, 1987, p. 87).

En 1906 Hudson fue electo director de la Compañía Royal Marmórea Danesa S. A. de México, que poseía los derechos de patente en México para manufacturar mármol artificial..$^{22}$ Con un capital social que alcanzaba los 250000 pesos, el negocio era propiedad de William V. Backus. Según Hart (2002), se trataba de un holding que poseía, a su vez, otras compañías como la Tuxpan Valley Rubber Estates, la Imperal Plantation Company, la Mexican Investment and Manufacturing Company y la Federal Plantation Company, todas ellas poseedoras de 5099 hectáreas en la región de Tuxpan y vinculadas con la explotación del caucho (p. 207).

Ese mismo año colaboró en la fundación del Mexico City Banking Company, S. A. en compañía de A. A. Robinson, entonces presidente de la Mexican Central Railway. En 1907 Hudson ocupó el cargo de director de un negocio que tenía representaciones en Chicago, Dallas, El Paso, Hong Kong, Madrid, Nueva York, París, San Francisco y San Luis, que poseía un capital

21 “Auge financiero en México”, El Diario, 13 de octubre de 1906, p. 3.

22 “Compañía Royal Marmórea Danesa S. A. de México", El Diario, 18 de diciembre de 1906 , p. 5. 
social de 400000 pesos y que contaba con ganancias cercanas a los 134000 pesos anuales, mismas que alcanzaron los 218000 pesos en $1909 .^{23}$

En octubre de 1907 El Correo Español publicó una nota sobe la Convención Nacional Hulera. Esta se celebró en el salón de recepciones del Herald y Paul Hudson fue tanto uno de los convocantes como uno de sus oradores. Si bien la nota es escueta en información, al menos pone en evidencia la relación entre él y una de las industrias que más creció durante el porfiriato: la del hule. ${ }^{24} \mathrm{Al}$ respecto, Schell (2001) destaca el papel fundamental que tuvo Hudson en este ramo, pues, además de ser su presidente, ayudó a la creación de la Mexican Association of Rubber Planters "para restaurar la credibilidad de las inversiones en las plantaciones tropicales que habían sido lastimadas severamente por reportes de fraude generalizado" (p. 17).

A las actividades económicas y periodísticas, Hudson sumó otras que en mucho le ayudaron a alcanzar una posición preeminente en el seno de la colonia estadunidense de la ciudad de México: las sociales.

Empezaremos por señalar que, a menos de un año de residir en el país, se involucró de lleno en las actividades sociales de esta. Los periódicos The Two Republics y The Evening Telegram hacían mención constante de su asistencia a los partidos de beisbol y futbol americano y a las fiestas organizadas por los hombres más connotados de esta comunidad.

En 1897 se integró en el American Club of Mexico (АCM) y en 1901 obtuvo el nombramiento de secretario. ${ }^{25}$ Esta era una organización creada en 1895 y aunque en sus estatutos señalaba que era la más representativa de la comunidad estadunidense, los 100 dólares de inscripción y los 50 correspondientes a la anualidad la alejaban mucho de serlo (Schell, 2001, p. 74) ${ }^{26}$ En realidad, fue un club de tendencia aristocrática en el que algunos mexicanos podían tener cabida en la medida en que sus actividades, y su cartera, interesaran a los hombres de negocios estadunidenses.

23 “Mexico City Banking Company, S. A.", The Mexican Herald, 23 de abril de 1909, p. 11.

${ }^{24}$ William Schell señala que para 1912 los estadunidenses controlaban $68 \%$ del negocio de hule en México que, a su vez, representaba 50\% de las propiedades agrícolas en manos estadunidenses más capitalizadas.

25 "Elecciones en el Club Americano", El Imparcial, 26 de diciembre de 1901, p. 3.

${ }^{26}$ Un dato interesante que proporciona Shell es que así como algunos mexicanos eran bien recibidos, los estadunidenses de color podían ser miembros bajo el famoso principio de "iguales pero separados". Curiosamente Paul Hudson, quien era hijo de un general abolicionista, aceptó con agrado esta disposición.

\section{()(1) $(9$}


Al inicio de 1898 el nombre de Hudson apareció continuamente en diversos periódicos. La guerra hispano-estadunidense se peleaba en Cuba y hacía más de un mes -el 15 de febrero- había acaecido el hundimiento del barco Maine. A mediados de marzo, "lo más conocido de la colonia americana", según El Imparcial, ${ }^{27}$ se reunió en el salón de la logia Odd Fellow para honrar la memoria de los muertos en el Maine y para organizar el levantamiento de un monumento en su honor. En esta ocasión Hudson quedó a cargo del comité de suscripciones, de tal manera que de él dependía la recaudación de los fondos necesarios para su construcción. Sabemos que no sólo contribuyó con su trabajo pues también dio un donativo por la nada desdeñable cantidad de 1000 pesos.

Entre 1902 y 1912 se convirtió en un asiduo organizador de los festejos del 4 de julio. Con motivo de la celebración del día de la independencia de Estados Unidos, un pequeño grupo de hombres destacados del ACM solía reunirse en algún hotel de la ciudad de México para formar el comité encargado del evento. En ocasiones las fuentes nos refieren el cargo ejercidio por Hudson (secretario, por lo general), mientras que en otras se limitan únicamente a mencionar su participación, pero sin especificar el tipo de actividades que desarrolló.

Resulta interesante observar cómo esta celebración empezó a tener una gran relevancia para la comunidad estadunidense a partir de la guerra hispano-estadunidense. Si bien la organización del festejo estaba a cargo del ACM, en 1903 fue fundada la Society of the American Colony (sAC), que se constituyó en una agrupación más abierta e incluyente que hizo las veces de competencia del ACM en lo referente a la celebración del día de la independencia de Estados Unidos.

A final de cuentas, las tensiones entre ambas organizaciones fueron cediendo y el presidente de la sAC gozaba en la comunidad del mismo reconocimiento y prestigio que el embajador de Estados Unidos, hecho que, según Schell (2001), se hizo público en un evento celebrado en el edificio del Herald en 1910 y del que nuestro personaje se vio beneficiado al ser electo miembro de la mesa directiva de la SAC por un periodo de tres años. ${ }^{28}$

Lo anterior pone en evidencia que Hudson supo cómo moverse al interior de la comunidad estadunidense. Desarrolló las habilidades necesarias

27 “Un meeting americano", El Imparcial, 19 de marzo de 1898, p. 1.

28 "Directiva de la Sociedad de la Colonia Americana", El Tiempo, 13 de abril de 1910, p. 1.

\section{()(1) $(9$}


para reconocer el carácter endogámico de un sector de ella, el más importante, jugar con sus reglas y entender que para hacer negocios, lo mismo que para aumentar su prestigio personal, lo importante no era conocer a todos sus miembros, sino saber a quiénes debía tratar.

La prensa hizo eco de los esfuerzos que Hudson y otros hombres de negocios provenientes de Estados Unidos estaban realizando para fundar en la ciudad de México un centro educativo a la altura de sus similares en Estados Unidos. Este fue el origen de la American School Association, institución educativa que sigue vigente hasta nuestros días. En realidad, la American School se había fundado en 1888, cuando John Davids abrió un pequeño kínder en su domicilio, ubicado en el número 2 de la segunda calle de Iturbide. Fue tal el éxito de este esfuerzo, que la institución tomó el nombre de Mexico Grammar School, y tuvo que cambiar continuamente de ubicación a raíz del crecimiento constante de su matrícula. ${ }^{29}$ Finalmente, en 1905 un grupo de industriales estadunidenses la reorganizó, la capitalizó con 10000 dólares y ofreció sus servicios a 80 alumnos. ${ }^{30}$

Hudson fue nombrado su primer presidente. En un principio aspiró a que los cursos empezaran en el otoño de 1905 para que coincidieran con el calendario escolar de Estados Unidos. Desconocemos el desarrollo de su gestión a la cabeza del proyecto, pero lo que sí sabemos es que respetó sistemáticamente los estatutos de la asociación al convocar en tiempo y forma a la asamblea general ordinaria por lo menos hasta $1909,{ }^{31}$ año al que corresponde el último registro hemerográfico que encontramos.

Ahora bien, su presencia en el ámbito de lo social también tuvo un viso humanitario cuyos beneficios pudieron disfrutar tanto los estadunidenses como los mexicanos. Este proceder era común en el porfiriato, época en la que la filantropía se desplazó de la caridad religiosa hacia la responsabilidad compartida entre el poder público y la sociedad y en donde se deseaba que esta tuviera cada vez un mayor peso, tal como lo enunció en 1885 Manuel Romero Rubio, entonces secretario de Gobernación, al expresar que "la beneficencia privada era el medio más seguro y natural de socorrer a los necesitados" (González Navarro, 1990, p. 499). De igual manera, Fernández y

${ }^{29}$ Véase The American School Foundation, http://solutions.asf.edu.mx/125years/

30 "American School assured", Los Angeles Herald, 19 de abril de 1905, p. 3; Scanlon (1984, p. 39).

31 “The American School Association”, El Diario, 9 de enero de 1909, p. 4.

\section{()(1) $(9$}


Lluch (2015) sostienen que en este tiempo el gobierno mexicano alentó a las familias adineradas y a los inversores extranjeros para que encabezaran iniciativas de corte asistencial.

En su conjunto, estos ejercicios eran pensados para ayudar a paliar, que no para resolver, algunos problemas estructurales y formaban parte de una estrategia de la administración porfirista concebida para otorgarle cierta legitimidad al régimen a través de la construcción de la imagen de un México solidario y en continuo progreso.

En octubre de 1906, la Sociedad de Jóvenes Cristianos (Young Men's Christian Association o YMCA) organizó su banquete anual en el prestigioso Hotel Sanz y contó con la presencia de algunos personajes extranjeros y mexicanos de renombre, entre los que se encontraban el vicepresidente de México, Ramón Corral, el embajador de Inglaterra, Reginal Tower, el empresario Francisco Boker, el coronel Félix Díaz, Guillermo Landa y Escandón, gobernador del Distrito Federal, y, claro está, Paul Hudson.

Esta reunión distó de ser igual a las anteriores pues en ella el secretario general del Comité Internacional de la YMCA, el estadunidense John R. Mott, ofreció 50000 dólares a la Junta Directiva de la organización en México a cambio de que esta diera una suma similar para "construir un edificio, con mobiliario para las dos ramas, mexicana e inglesa". ${ }^{32}$ No conforme con ello, Mott leyó una relación con los nombres de los miembros que conformarían el comité encargado de recolectar los fondos necesarios para concretar el proyecto. La lista comprendía tanto a nacionales como a extranjeros de renombre, de tal manera que al nombre de Paul Hudson se sumaron los del coronel Félix Díaz, el gobernador Guillermo Landa y Escandón, los empresarios Óscar Braniff y A. H. Mckay, el abogado Juan Dublán y el general J. B. Frisbie, entre otros.

Para diciembre de 1906 se habían recolectado 166000 pesos que, casi en su totalidad, fueron aportados por miembros de la comunidad estadunidense. Según lo publicado por El Popular, el rango de las suscripciones -o contribuciones- individuales era el siguiente: 100 000, 10 000, 5 000, 1000 y 500 pesos. ${ }^{33}$ En tanto que Mott fue el único en dar la primera cantidad, la aportación de Hudson fue mucho más discreta pues constó de tan sólo 1000 pesos. Sin embargo, ello no fue obstáculo para que una vez que la YMCA com-

\footnotetext{
32 "En la Asociación Cristiana de Jóvenes", El Diario, 21 de octubre, p. 2.

33 “Asociación Cristiana de Jóvenes”, El Popular, 19 de diciembre de 1906, p. 2.
}

\section{()(1) $(9$}


pró el terreno para levantar el edificio -en la esquina de la calle Morelos y la avenida Balderas-, el estadunidense formara parte del comité encargado de su construcción. El 16 de junio de 1909, el general Porfirio Díaz colocó la primera piedra de la obra en una ceremonia a la que asistieron varios invitados, entre ellos Hudson, y un año más tarde regresó para inaugurar un edificio cuyo costo se estimaba en unos 330000 pesos. ${ }^{34}$

Hudson también se sumó a otros proyectos filantrópicos destinados única y exclusivamente a los grupos menos favorecidos de México. He ahí el caso de la Asociación Protectora de los Niños sin Hogar, institución creada en noviembre de 1911 para sumar "su poderosa influencia a beneficio de tantos rapazuelos que a diario ofrecen el doloroso cuadro de dormir en los quicios de las puertas, arropados por periódicos" ${ }^{35}$ Se trataba de una iniciativa organizada por filántropos de Estados Unidos y de México que contaba con una mesa directiva que tenía como presidente de facto a Carlos B. Zetina, y como honorífico a Pedro Lascuráin, ministro de Relaciones Exteriores, y en la que Hudson y otros miembros de la colonia estadunidense hicieron las veces de vocales.

Los trabajos de la asociación rindieron sus frutos cuando el 9 de agosto de 1912 sus miembros inauguraron el dormitorio para los niños pobres, situado en el número 143 de la calle de Donceles. En la ceremonia Lascuráin ofreció un discurso en el que hizo mención de los motivos de la asociación para realizar aquella obra y dio los pormenores financieros de la misma. Asimismo, hizo notar la participación mayoritaria de los estadunidenses en el proyecto. El periódico El País publicó una nota de dos páginas en la que consignó este hecho y que coronó con una foto de los directivos de la asociación y en la que Hudson aparecía sonriente. ${ }^{36}$

34 "Nuevo edificio", El Popular, 13 de julio de 1907, p. 2.

35 "La Asociación Protectora de Niños sin Hogar", El Imparcial, 4 de noviembre de 1911, p. 5.

${ }_{36}$ Se trata de la única foto de Hudson que encontramos publicada en un periódico. No obstante, el pie de la foto está errado pues indica que Hudson es el primero de izquierda a derecha cuando, en realidad, es el último en ese sentido. "Se inauguró el dormitorio para los niños que carecen de hogar”, El País. Diario Católico, 10 de agosto de 1912, p. 8.

\section{()(1) $(3$}




\section{EL CREPÚSCULO CAE SOBRE PAUL HUDSON (1911-1921)}

Los tiempos difíciles para Hudson empezaron a gestarse en 1910 con la llegada del nuevo embajador de Estados Unidos en México: Henry Lane Wilson. Aunque en un principio la relación que Hudson mantuvo con él era similar a la que había sostenido con los antecesores del diplomático, el inicio de la revolución mexicana llevó a que ambos compartieran posturas e intereses.

En noviembre de 1910, y a unos pocos días del inicio del movimiento revolucionario de Francisco I. Madero, Hudson volvió a ponerse al servicio del régimen porfirista y recurrió a los servicios de AP, en la que su presencia era fuerte, para enviar informes a distintos periódicos de la unión americana en los que minimizaba lo que acontecía en el país. The Spartanburg Herald, de Carolina del Sur, publicaba el 25 de noviembre un telegrama que había recibido de él y que sentenciaba que "los reportes provenientes de la frontera exageran. Los informes oficiales señalan que las fuerzas gubernamentales son optimistas y suficientemente capaces para controlar la situación en los estados del norte. ${ }^{37}$ La renuncia de Porfirio Díaz el 25 de mayo de 1911 puso de manifiesto que en aquellos comunicados que Hudson desmintió había mucho de verdad y poco de exageración.

El ascenso de Madero al poder marcó un cambio en las relaciones que Hudson y Wilson sostenían con el poder ejecutivo mexicano. En su libro Las invasiones norteamericanas a México, García Cantú (1986) retoma un conjunto de cinco artículos publicados por el periódico veracruzano El Pueblo entre el 18 de mayo y el 21 de junio de 1916 para analizar la situación y señalar que el rechazo de ambos hacia el nuevo gobierno fue evidente desde un principio pues "la prosa del embajador norteamericano tiene exacta correspondencia con las difamaciones públicas del Mexican Herald” (p. 252). De hecho, mientras Wilson fue embajador de Estados Unidos en el país, Hudson fue considerado como uno de sus más estrechos colaboradores.

En lo que se refiere a Hudson, Madero decidió plantarle cara desde dos frentes. Primero, le retiró al Herald y al Heraldo Mexicano el subsidio que Díaz les había otorgado. ${ }^{38}$ Después, cambió el convenio que la administración había fijado verbalmente con la AP por uno escrito y menos ventajoso para la agencia informativa, lo que llevó al estadunidense a demandar al go-

\footnotetext{
37 "Reports Exaggerated", The Spartanburg Herald, 25 de noviembre de 1910, p. 1.

38 "El asunto del Heraldo Mexicano", El Tiempo, 17 de abril de 1912, p. 8.
}

\section{()(1) $(9$}


bierno mexicano, con el apoyo de Wilson, el pago de 200000 pesos a manera de compensación (García Cantú, 1986, p. 269).

El golpe más fuerte que recibió de la administración maderista tuvo lugar el 29 de marzo de 1912 cuando la policía allanó las oficinas de El Heraldo de México, confiscó sus bienes y suspendió sus actividades. Aunque este movimiento lo tomó por sorpresa, supo reaccionar con prontitud. Aprovechó el derecho de réplica que le dieron algunos diarios de la capital, como El Tiempo, para minimizar el cierre del periódico al afirmar que este se debía a causas económicas y no a las diferencias que sostenía con el gobierno del presidente Madero; ${ }^{39}$ pero, al mismo tiempo, recurrió a sus amigos de la prensa en Estados Unidos para publicar otra versión de lo acontecido, una en la que la clausura correspondía al malestar de las autoridades mexicanas y en la que manifestaba que "hemos sido víctimas de un proceder arbitrario e ilegal". ${ }^{40}$ Como consecuencia de lo anterior, los medios al norte del río Bravo salieron a la defensa de Hudson al presentarlo como víctima de uno de los peores errores cometidos por Madero pues, a final de cuentas, el estadunidense "tiene mucho que ver con el maravilloso crecimiento de México [...]. Él simplemente dio toda la ayuda que pudo a las iniciativas educativas e industriales. La destrucción de su propiedad no sólo fue ilegal, fue un acto de gran ingratitud". ${ }^{41}$

Todos estos hechos marcaron profundamente a Hudson. A partir de ese momento se convirtió en un promotor de la intervención militar de Estados Unidos para restaurar el orden y defender sus intereses en México. En plena Decena Trágica declaró que se había negado a publicar un comunicado del presidente Taft en el que aseguraba que sólo intervendría en México si los ciudadanos de Estados Unidos eran atacados de manera deliberada por los revolucionarios. ${ }^{42}$ Para él, aquellas palabras eran motivo de vergüenza.

En cierto sentido, la manera como Hudson vivió la Decena Trágica sirvió para que radicalizara su postura. Entre el 11 y el 13 de febrero él, su esposa $\mathrm{y}$ dos de sus hijos tuvieron que atrincherarse en las oficinas del Herald -que sólo suspendió sus actividades el día 13-, para protegerse del intercambio de cañonazos entre las facciones leal y rebelde. ${ }^{43}$ Por ello, no es de extrañar que

39 “El asunto del Heraldo Mexicano”, El Tiempo, 17 de abril de 1912, p. 8.

40 S. T., The Herald Democrat, 30 de marzo de 1912, p. 1.

41 “Madero's Mistake”, The Herald Democrat, 11 de abril de 1912, p. 4.

42 “President Madero has not resigned”, Utica Herald Dispatch, 13 de febrero de 1913, p. 3.

43 "Rebel's fire is centered on Palace, Madero stronghold", The Herald Democrat, 14 de febrero de 1913, p. 2. 
el ascenso de Victoriano Huerta al poder representase un momento de calma y entendimiento entre ambos personajes. Si bien publicó en el Herald que no justificaba la forma como el general mexicano había llegado al ejecutivo nacional, en la práctica se convirtió en uno de los mayores promotores de su reconocimiento por parte del gobierno estadunidense. ${ }^{44}$

A partir de ese momento, Hudson se volvió un acérrimo defensor tanto del embajador Wilson como de Huerta. Sobre el primero, formó parte de la comisión que la colonia estadunidense envió a Washington con el fin de defender los actos cometidos por el diplomático durante la Decena Trágica y para solicitar su permanencia en el país. ${ }^{45}$ Sobre el mexicano, escribió al Washington Post una extensa declaración en la que invitaba a Woodrow Wilson, presidente desde el 4 de marzo de 1913, a que considerara al régimen de Huerta como el menor de los males. Sostenía que lo contrario generaría tal caos que Estados Unidos se vería obligado a intervenir en México por amor propio y para mantener la integridad de la Doctrina Monroe. ${ }^{46}$

A pesar de que sus palabras fueron desestimadas, no cesó en sus esfuerzos y escribió, junto con algunos hombres prominentes de la colonia, Un trato justo para México, manifiesto en el que sostenía la conveniencia de reconocer al gobierno huertista. A pesar de que varios diarios de Estados Unidos publicaran el documento, Hudson no logró cambiar la postura de las autoridades del país.

A inicios de 1914 se embarcó en el proyecto de crear una nueva asociación que ocupara el lugar de la National Association for the Protection of American Rights in Mexico, pues esta había sido un instrumento financiado por las compañías petroleras que respondía únicamente a sus intereses. La finalidad del comité ejecutivo provisional de esta asociación, del que Hudson formó parte, era "corregir los errores del pasado y restaurar los derechos en México", ${ }^{7}$ objetivo que implicaba, como condición necesaria, la intervención armada en el país.

Pese a ser uno de los mayores defensores de Huerta, Hudson no dudó en abandonar la capital del país, y llevarse con él su periódico, cuando las

\footnotetext{
44 "Rebel's fire is centered on Palace, Madero stronghold", The Herald Democrat, 14 de febrero de 1913, p. 2.

${ }^{45}$ S. T., El renovador, 23 de julio de 1915, p. 5.

46 "The Mexican situation", The Atlanta Constitution, 28 de mayo de 1913, p. 5.

47 "Form new company to protect U. S. in Mexico", The Milwaukee Sentinel, 14 de febrero de 1914 , p. 2.
} 
tropas estadunidenses ocuparon la ciudad de Veracruz en abril de 1914. Así, el 23 de abril de 1914 apareció el último número del diario en la capital del país, en tanto que dos días después, el 25, empezó a circular por las calles del puerto gracias a que se imprimía en los talleres del periódico católico La Opinión, del que el estadunidense era su nuevo director. Knopp (1973) apunta que el mismo día en que la publicación inició operaciones en Veracruz, una turba en la ciudad de México rompió las ventanas del edificio en el que se encontraban sus oficinas e intentó infructuosamente prenderle fuego.

A partir del 1 de agosto de 1914, y por motivos que desconocemos, el Herald volvió a imprimirse en la ciudad de México, lo que implicó, a su vez, que Hudson retornara a la capital del país. Aparentemente la entrada del ejército constitucionalista no fue un obstáculo para que el diario siguiera editándose; sin embargo, en diciembre de ese año Hudson fue arrestado por órdenes del gobernador del Distrito Federal, el general Chao, como consecuencia de la publicación de noticias que causaron el malestar del gobierno carrancista. Tres horas más tarde, fue liberado gracias a las gestiones del embajador de Brasil y del agente estadunidense Silliman. ${ }^{48}$

Lo anterior tan sólo fue el preámbulo de un problema mayor que vivieron en carne propia Hudson y su familia. En enero de 1915 el general Venustiano Carranza trasladó la sede de su gobierno al puerto de Veracruz, con lo que dejó la capital del país en manos de las tropas villistas y zapatistas. Si bien no encontramos noticias sobre nuestro personaje entre enero y junio de ese año, suponemos que no cambió su postura en torno a los revolucionarios, que hizo del Herald un eco de las mismas y que, en consecuencia, sus relaciones con las autoridades en la ciudad de México no debieron ser cordiales.

Desde la perspectiva anterior adquieren sentido los sucesos que tuvieron lugar en la ciudad de México el 25 de julio de 1915. Por la tarde, las tropas zapatistas entraron al edificio del Herald, se apoderaron de las imprentas para publicar su periódico -El Renovador-, y aprisionaron a Hudson y a su familia en compañía de algunos de sus colaboradores más cercanos bajo la amenaza de ser juzgados por una corte marcial. La noticia fue dada a conocer en Estados Unidos por diversas publicaciones que abrevaron de la misma fuente: un cable enviado a Galveston, Texas.

\footnotetext{
48 "Bulletins", The Herald Democrat, 24 de diciembre de 1914, p. 1; "Desacuerdo con el llamado presidente de la convención y los zapatistas”, El Pueblo, 25 de diciembre de 1914, p. 2.
}

\section{()(1) $(9$}


Varios periódicos al norte del río Bravo dieron a conocer la información y los esfuerzos realizados por los familiares y amigos de la familia Hudson para que el presidente Wilson actuara. Este no dudó en pasar el caso al Departamento de Estado con la instrucción de que hiciera lo necesario para la pronta liberación de los presos. La entrada de Carranza a la ciudad de México, el 2 de agosto de 1915, facilitó las gestiones para que Hudson, su familia y sus colaboradores fueran liberados. ${ }^{49}$

Al entrar a la ciudad de México, Carranza había salvado la vida a Hudson, cierto, pero el estadunidense tuvo que pagar un precio alto a cambio. El revolucionario ordenó el cierre de The Mexican Herald y declaró a Hudson como persona non grata..$^{50}$ Después de 21 años de existencia, el Herald vio la luz por última vez el viernes 25 de octubre de 1915. Poco menos de un mes más tarde, él y su familia partieron rumbo a Estados Unidos.

La salida de Hudson no fue motivo suficiente para que la prensa nacional se olvidara en el corto plazo de él. Entre mayo y junio de $1916 \mathrm{El} \mathrm{Pueblo,}$ que en el pasado había mostrado respeto por él, publicó cinco artículos en los que lo calificaban de "malévolo", "pérfido", "traidor"... por dos motivos: haber apoyado la dictadura de Victoriano Huerta y ser miembro del Comité de los Cien. Según el periódico, este grupo fue organizado en El Paso, Texas, por 100 hombres de negocios de Estados Unidos que habían hecho su fortuna en el porfiriato y que buscaban enviar informes a las convenciones demócrata y republicana de lo que pasaba en México. Como era un año de elecciones, se especulaba que querían que quien quedara como presidente del país -a la postre Wilson se reeligió- protegiera moral y económicamente los intereses estadunidenses en México. ${ }^{51}$

Aunque la evidencia no nos permite afirmar que Hudson formara parte de dicho comité, es inobjetable que siempre se mostró interesado por lo que acontecía en México y no ocultó sus deseos de volver al país para regularizar lo que quedaba de sus negocios. Es más, a mediados de 1917 retornó a la ciu-

49 “Americans are prisoners in Mexico City", Desert Evening News, 31 de julio de 1915, p. 1; "Americans put in Mexican prison", The Day, New London, 31 de julio de 1915, p. 1; "Appeal to President to save editor", The Ogdensburg Journal, 31 de julio de 1915, p. 1; "Leaves are diet of Mexican Poor", Berkeley Daily Gazette, 2 de agosto de 1915, p. 4; "Villa to abandon Torreon", Desert Evening News, 2 de agosto de 1915, p. 2; "Will send food to Mexico City", Spokane Daily Chronicle, 2 de agosto de 1915, p. 12.

50 "Mexico entry is postponed by Carranza", Los Angeles Herald, 18 de agosto de 1915, p. 7.

51 “El comité de los cien...", El Pueblo, 21 de junio de 1916, p. 2.

\section{()(1) $(9$}


dad de México e inició las gestiones para reanudar la publicación del Herald aprovechando que las oficinas y talleres tipográficos del periódico habían permanecido intactos desde su partida.$^{52}$ Los permisos jamás llegaron y el proyecto quedó en el olvido.

A partir de este momento, las menciones de Hudson en la prensa van decreciendo en número y sólo las encontramos en los periódicos al norte del río Bravo. Sabemos que al inicio de los años veinte fundó en compañía del petrolero William Frank Buckley la American Association of Mexico. Con oficinas en Nueva York y Washington, la organización tenía como objetivo central representar a los pequeños inversores y grandes compañías que no se sentían identificadas con la National Association for the Protection of American Rights in Mexico. Se trataba de un ejercicio con fuertes connotaciones coyunturales dado que sus fundadores solicitaban que Estados Unidos sólo reconociera a la administración de Álvaro Obregón si esta se comprometía a compensar por los daños sufridos a los ciudadanos estadunidenses en México y a restituirles sus propiedades. ${ }^{53}$

El tiempo había pasado pero Hudson seguía sosteniendo su rechazo a los regímenes revolucionarios, de ahí que, según lo refiere Baldridge (1971), se convirtiera en el operario político de Buckley en Washington mientras este se encontraba en México apoyando el levantamiento fallido del general Manuel Peláez contra Álvaro Obregón. Lamentablemente para su causa, el movimiento fracasó y Buckley fue expulsado del país.

A partir de este momento perdemos la pista a Paul Hudson. Nuestras fuentes cesan de nombrarlo, guardan un profundo silencio que no hace más que dejarnos dudas en torno a sus últimos diez años de vida.

\section{CONCLUSIONES}

Como hemos podido estudiar a lo largo de estas páginas, la figura de Paul Hudson se nos manifiesta como multifacética al tiempo que polémica. Por un lado, a las actividades propias de la dirección de The Mexican Herald hallamos otras vinculadas con los negocios, la educación y la filantropía; por el otro, su postura manifiestamente contraria hacia la revolución mexicana

\footnotetext{
52 “El fantasma del hambre en México”, El Paso Morning Times, 9 de octubre de 1917, p. 1.

53 “Oilmen Form Association”, Longmont Ledger, 18 de febrero de 1921, p. 2.
}

\section{()(1) $(9$}


facilitó que sus detractores le pusieran el epíteto, entre otros, de "traidor" a México.

Como gerente y presidente de The Mexican Herald, Hudson logró dar vida a uno de los principales periódicos del país y, sin lugar a dudas, el más importante escrito en lengua extranjera, de modo que su lectura era casi obligatoria para quienes quisieran realizar negocios en México.

Se encargó de que el periódico fuera un ejemplo del modelo de periodismo estadunidense en México, y del que El Imparcial fue el primer representante mexicano en castellano. Tal vez este hecho, aunado a los servicios presentados el régimen, nos permita comprender la afinidad que existía en ambas publicaciones pues son varias las ocasiones en las que los nombres de los dos diarios se hallan asociados en buenos términos.

Supo que los avances tecnológicos, así como el desarrollo material que estaba teniendo lugar en México, podían actuar a favor de su periódico en un momento en el que la prensa bien podía llegar a ser un negocio económicamente redituable. En este sentido, reconocemos que uno de sus mayores aportes para el periodismo de su tiempo fue el haber conseguido que The Mexican Herald fuera el primer diario en el país en hacerse de los servicios telegráficos de la agencia estadunidense Associated Press y que fuera uno de los miembros fundadores de la sucursal de la agencia noticiosa en la capital.

Debemos reconocer que este y otros logros de Hudson en el campo del periodismo se debieron al apoyo recibido por parte del gobierno porfirista, mismo que no se limitó exclusivamente a la cuestión de los subsidios. A manera de ejemplo indicaremos que Hudson nutría a su periódico con noticias provenientes de la Associated Press a través del uso del sistema telegráfico federal, probablemente de la línea entre Laredo y la ciudad de México. Este acceso privilegiado hacía las veces de recompensa por los servicios prestados por el periódico a la par que marcaba la diferencia entre The Mexican Herald y su competencia, al menos hasta que se abrieron las oficinas de la agencia en 1906.

En lo que se refiere al ámbito de los negocios, Schell sostiene que Hudson fue uno de los miembros más importantes de la "mafia tropical". Entendemos que su inclusión en cualquier negocio era un beneficio que no se podía desdeñar en virtud del prestigio del que gozaban al interior de la comunidad estadunidense él y su periódico. Sin embargo, ello nos deja más preguntas que certezas: ¿fue propietario o copropietario de alguna de estas empresas?, ¿hizo las veces de intermediario entre los inversores extranjeros y mexica-

\section{()(1) $(9$}


nos?, ¿fue socio capitalista, industrial o ambos?, ¿qué beneficios económicos y sociales concretos obtuvo de su participación en estos negocios?

En lo filantrópico y social su nombre alcanzó gran relevancia en el seno de la comunidad estadunidense. Un aspecto que consideramos de interés es que solía formar parte de las comisiones encargadas de la recaudación de fondos para la realización de los proyectos, labor nada sencilla si se considera que no sólo demandaba un cierto tipo de habilidades (expresión, persuasión, organización...), también tener un acceso franco a los hombres de negocios más importantes de la comunidad estadunidense. En tanto que lo primero se trata de una cuestión personal, lo segundo es de carácter social y, precisamente, lo consideramos como una evidencia más de los vínculos existentes entre Hudson y los grandes capitales estadunidenses en México.

En cuanto a la perspectiva de Hudson como "traidor" de México, encontramos que esta se gestó con la revolución mexicana a raíz de cuatro momentos: su colaboración con el régimen de Porfirio Díaz (1896-1911), su cercanía con Henry Lane Wilson (1910-1913), su apoyo al gobierno de Victoriano Huerta (1913-1914) y sus gestiones en Estados Unidos (1915-1921). Mientras que el primero y parte del segundo se dio durante el porfiriato, los restantes se enmarcan en plena lucha armada y en la posrevolución. Durante la revolución, los detractores de Hudson encontraron motivos más que suficientes para acusarlo de traición pues desde su llegada a México, siempre se había mostrado contrario a lo que los revolucionarios consideraban que eran los genuinos intereses del pueblo mexicano.

Cierto es que no ocultó su repudio al movimiento revolucionario desde sus inicios. Al igual que Wilson, rechazó la llegada de Madero al poder ejecutivo nacional y aceptó el ascenso de Victoriano Huerta, a quien vio como un restaurador del orden pasado, una especie de sucedáneo de Porfirio Díaz. Ello no sólo quedó puesto de manifiesto en las páginas del Herald, también marcó un cambio en su línea editorial. Si con en el porfiriato el diario había intentado mediar entre los gobiernos de México y Washington y fomentar la cooperación entre ambas naciones, entre 1911 y 1913 imperó en sus páginas la retórica de la violencia basada en la necesidad de que Estados Unidos invadiera a México para imponer el orden. Este ejercicio implicaba, por supuesto, la defensa de los intereses económicos de la colonia estadunidense en México. En ese sentido, Hudson mostró tener un mayor interés en lo económico que en lo altruista y lo periodístico. Sus reclamos y acciones entre 1915 y 1921 no denotaban un auténtico interés por la prensa (pese a intentar reeditar su

\section{()(1) $(9$}


diario en 1917); por el contrario, seguían el camino del dinero, la empresa y el negocio y en el que el Herald había sido una pieza más.

El presente texto es apenas un pequeño bosquejo en torno a la figura de Paul Hudson, esbozo que podemos ir afinando al ampliar nuestra búsqueda documental a otros espacios, entre ellos el Archivo General de la Nación de México, el Archivo General de Notarías de la Ciudad de México, el archivo de la Kansas Historical Society y los National Archives de Washington. El ejercicio bien vale la pena no sólo para saber más en torno a nuestro personaje, también para tener una mayor y mejor comprensión de un momento fundamental en la historia de México en el que los negocios y los periódicos empezaban a compartir los mismos intereses y personas y en el que la prensa se constituyó en un espacio de promoción y de difusión de los intereses políticos y financieros del grupo en el poder y de las elites que le rodeaban.

\section{LISTA DE REFERENCIAS}

Baldridge, D. C. (1971). Mexican petroleum and United States-Mexican relations, 19191923 (Tesis de doctorado inédita). University of Arizona, Estados Unidos.

Camp, S. (julio 28, 2014). Does Genealogy Illustrate History? Topeka \& Shawnee County Public Library. Recuperado de https://tscpl.org/history/today-in-genealogy

Collado, M. (1987). La burguesía mexicana. El emporio Braniff y su participación política. 1865-1920. México: Siglo XXI Editores.

Connelley, W. (1918). A standard history of Kansas and Kansans (vol. IV). Nueva York: Lewis Publishing Company.

Douglas, G. (1999). The Golden Age of the Newspaper. Westport, Connecticut: Greenwood Press.

Fernández Pérez, P. y Lluch, A. (2015). Familias empresarias y grandes empresas familiares en América Latina y España. Una visión de largo plazo. España: Fundación BBVA.

García Cantú, G. (1986). Las invasiones norteamericanas en México. México: SEP/ERA.

González Navarro, M. (1990). Historia moderna de México. El porfiriato. La vida social (vol. IV) ( $5^{\text {a } e d i c i o ́ n) . ~ M e ́ x i c o: ~ H e r m e s . ~}$

Hart, J. (2002). Empire and Revolution: The Americans in Mexico since the Civil War. Londres: University California Press.

\section{()(1) 3}


Knopp, A. K. (1973). The will of the people: International public opinion and the American intervention in Mexico (Tesis de doctorado inédita). Texas Tech Universtiy, Estados Unidos.

Knudson, J. (2001). The Mexican Herald: Outpost of empire, 1895-1915. International Communication Gazette, 63(5), 387-398. DoI: 10.1177/0016549201063005002

La Latinoamericana, Seguros de Vida, S. A: su historia de sesenta años, 1906-1966 (1996). México: Comisión Nacional Bancaria.

Lepidus, H. (1928). The history of Mexican journalism. The University of Missouri Bulletin, 29(4).

Mayagoitia, A. (2005). Crónica de cien años: The University Club of Mexico. México: UNAM.

Pérez-Rayón, N. (2001). México 1900. Percepciones y valores de la gran prensa capitalina. México: UAm Azcapotzalco/Miguel Ángel Porrúa.

Riguzzi, P. (1992). Estados Unidos y Gran Bretaña, 1867-1910: una difícil relación triangular. Historia Mexicana, 41(3), 365-436.

Scanlon, A. (1984). Un enclave cultural. Poder y etnicidad en el contexto de una escuela norteamericana en México. México: cIESAs.

Schell, W. (2001). Integral outsiders: The American colony in Mexico City, 1876-1911. Wilmintong, Delaware: SR Books.

Salyer, J. (2011). A community of modern nations: The Mexican Herald at the height of the porfiriato 1895-1910 (Tesis de doctorado inédita). East Tennessee State University, Estados Unidos.

Walton, G. y Rockoff, H. (2014). History of the american economy (12 ${ }^{\mathrm{a}} \mathrm{ed}$.). USA: Southwestern Publishing. 